\title{
Analisis Kekuatan Komposit Serat Kulit Kayu Jati Dengan Variasi Arah Serat
}

\author{
Supriyanto $^{1}$, Wasis Enggah Widianto ${ }^{2}$, Nuryosuwito ${ }^{3}$ \\ 1),2) Teknik Mesin Fakultas Teknik Unversitas Janabadra \\ 3) Teknik Mesin Fakultas Teknik Universitas Nusantara PGRI \\ E-mail : ${ }^{1)}$ supriyanto@janabadra.ac.id, ${ }^{2)}$ suwito.unp@gmail.com.
}

\begin{abstract}
Abstrak
Serat kulit kayu jati merupakan serat alami yang diperoleh dari pohon jati (Tectona Grandis), dan dapat terdegradasi secara alami serta harganya lebih murah dibanding serat sintetis. Tujuan dari penelitian ini untuk mengetahui Karakteristik Kekuatan Komposit Serat Kulit Kayu Jati Dengan Variasi Arah Serat.Pada penelitian ini dilakukan pemilihan serat yang baik. kemudian serat kulit kayu jati direndam dalam larutan $\mathrm{NaOH}$ dengan kadar 5\% selama 60 menit dan dibilas dengan air bersih kemudian dikeringkan. Selanjutnya dipotong dengan panjang $200 \mathrm{~mm} \times$ lebar $5 \mathrm{~mm}$ untuk uji tarik, dan untuk uji impack panjang $80 \mathrm{~mm} \times$ lebar $5 \mathrm{~mm}$. Lebih lanjut, pembuatan komposit menggunakan pencampuran menggunakan perbandingan serat kullit kayu jati $30 \%$ dan resin polyester70\% dari seluruh berat spesimen. Dari masing-masing pengujian menggunakan 12 spesimen yang terdiri dari serat kulit kayu jati, baik untuk uji tarik, dan uji impack dengan variasi arah serat unidirectional (serat lurus), pseudoisotropic (serat acak), bidirecitional (serat anyam). Berdasarkan hasil pengujian komposit serat kulit kayu jati yang sudah dilakukan dan diperoleh kesimpulan bahwa rata-rata kekuatan tarik arah serat anyam ini yang memeiliki nilai rata - rata tarik dan regangan paling tinggi dari variasi lain yaitu 22,58Mpa dan regangan $3,86 \%$. Komposit dengan arah serat lurus memiliki nilai rata - rata tegangan tarik 20,57 Mpa dan regangan 3,5\%, komposit dengan nilai terendah adalah variasi arah serat acak yaitu 12,14 Mpa dan regangan $1,75 \%$. Sedangkan untuk uji impack energi terserap rata-rata impack terbesar mencapai 0,56 Joule dengan arah serat lurus. Dan harga impack rata-rata yang dihasikan menggunkan serat lurus juga mendapat nilai kekuatan impack yang paling maksimal yaitu 0,0061 $\left(\mathrm{J} / \mathbf{m m}^{2}\right)$.
\end{abstract}

Kata kunci: Komposit, Serat Kulit Kayu Jati, Uji Tarik, Uji Impact.

\begin{abstract}
Teak bark fibers are natural fibers obtained from teak trees (Tectona Grandis), and can be degraded naturally and are cheaper than synthetic fibers. The purpose of this study was to determine the Power Characteristics of Teak Bark Composite Strength with Fiber Direction Variation. In this study a good fiber selection was conducted. then teak bark fiber is soaked in a 5\% $\mathrm{NaOH}$ solution for 60 minutes and rinsed with clean water and then dried. Next cut with a length of $200 \mathrm{~mm} x$ width $5 \mathrm{~mm}$ for a tensile test, and for an impack test of $80 \mathrm{~mm}$ length $x 5 \mathrm{~mm}$ width. Furthermore, making composites using mixing using a ratio of $30 \%$ teak kullit fiber and polyester resin $70 \%$ of the entire weight of the specimen. From each test using 12 specimens consisting of teak bark fibers, both for tensile tests, and impack tests with variations in the direction of unidirectional fibers (straight fibers), pseudoisotropic (random fibers), bidirecitional (woven fibers). Based on
\end{abstract}


the results of teak wood fiber composite testing that has been done and the conclusion is that the average tensile strength of this woven fiber has the highest tensile and strain values of other variations, $22.58 \mathrm{MPa}$ and $3.86 \%$ strain. Composites with straight fiber direction have an average value of tensile stress of $20.57 \mathrm{MPa}$ and a strain of 3.5\%, composites with the lowest value are random fiber direction variations of $12.14 \mathrm{MPa}$ and strain $1.75 \%$. Whereas for the impack test the energy absorbed by the average impack was the largest reaching 0.56 Joules in the straight fiber direction. And the average impack value produced using straight fiber also gets the maximum value of impack strength that is $0.0061(\mathrm{~J} / \mathrm{mm} 2)$.

Keywords: Composite, Teak Bark, Tensile Test, Impact Test.

\section{PENDAHULUAN}

Perkembangan teknologi material di Indonesia yang meningkat pesat sejalan dengan pertumbuhan ekonomi nasional, harus diimbangi dengan penyediaan material itu sendiri. Komponen utama dalam membuat suatu barang adalah material yang juga ikut menentukan kualitas barang yang diproduksi. Bila tidak ada perkembangan teknologi dan penemuan bahan baru maka tidak akan ada inovasi atau produk baru [1].

Dengan berkembangnya teknologi, manusia mampu menemukan hal baru baik yang belum pernah terungkap dan bahkan yang merupakan kombinasi dari bahan yang sudah ada seperti komposit. Komposit merupakan salah satu jenis bahan yang dibuat dengan penggabungan dua atau lebih macam bahan yang mempunyai sifat berbeda menjadi satu material baru dengan sifat yang berbeda pula. Komposit mempunyai keunggulan seperti kuat, ringan, tahan korosi, ekonomis dan ramah lingkungan sehingga dapat menjadi bahan alternatif selain logam dan fiber glass yang tidak ramah lingkungan[2].

Serat alam yaitu serat yang berasal dari alam (bukan buatan atau pun rekayasa manusia). Serat alam atau bisa dibilang sebagai serat alami ini yang biasanya didapat dari serat tumbuhan (pepohonan) seperti pohon bambu, pohon kelapa, pohon pisang serta tumbuhan lain yang terdapat serat pada batang maupun daunnya. Serat alam yang berasal dari binatang, antara lain sutera, ilama dan wool. Serat mineral diperoleh dari bahan tambang dari perut bumi contohnya asbestos. Serat sintesis merupakan hasil pengolahan bahanbahan kimia yang dilakukan di pabrik. Penelitian dan penggunaan serat alami berkembang dengan sangat pesat ini karena serat alami banyak memiliki keunggulan dibandingkan dengan serat buatan 
(rekayasa), keunggulan dari serat alami seperti beban lebih ringan, bahan mudah didapat, harga relatif murah dan yang paling penting ramah lingkungan terlebih Indonesia memiliki kekayaan alam yang begitu melimpah[3]. Penggunaan serat alami ini sudah merambah berbagai bidang kehidupan manusia, layaknya serat buatan, serat alami juga mampu digunakan sebagai modifikasi dari serat buatan.

Pohon Jati (Tectona Grandis) merupakan jenis tanaman yang sangat dikenal oleh penduduk Indonesia,Selain banyak ditemukan di Indonesia terutama di jawa, hutan jati juga banyak tumbuh di Negara-negara di Asia terutama di India, Thailand, Malaysia, dan Negara Indochina lainnya (Indochina ialah Negara yang terletak di Asean)[4].Hutan jenis ini mudah ditemukan di daerah-daerah yang sering mengalami kekeringan, jauh dari sumber air, atau di daerah dataran tinggi. karena pohon ini memiliki kemampuan hidup yang baik, meski jarang atau minim air di wilayah tersebut. Bagi sebagian orang pohon jati sangat banyak pemanfaatannya mulai dari daun hingga akar. Daunnya dimanfatkan sebagai bungkus makanan, rantingnya sebagai kayu bakar, kayunya sebagai furniture, akarnya sebagai bahan pewarna alami dan kulit kayunya hanya di manfaatkan sebagai pelapis dinding atau tembok.

Serat alam mempunyai beberapa keuntungan yaitu: lebih ringan, biaya produksi lebih rendah, kekuatan dan kekauan yang lebih tinggi, ketersedian bahan yang cukup melimpah, serta merupakan bahan yang dapat diperbarui. Kekuatan matrial komposit serat alam sangat dipengaruhi oleh karakteristik serat alam, karakteristik matriks dan ikatan antara serat alam dan mertiks. Serat biasanya mempunyi kekuatan dan kekakuan yang lebih besar dari metriks [5].

Berdasarkan uraian singkat diatas, penelitian ini dilakukan untuk mengetahui "karakteristik kekuatan komposit serat kulit kayu jati pada uji tarik dan pengujian impek dengan variasi arah serat. Tujuan dari analisa karakteristik kekuatan komposit tersebut adalah untuk mengetahui: (1) Rata - rata kekuatan tarik dan regangan komposit serat kulit jati dengan variasi arah serat sejajar, silang, dan anyam. (2) Hasil perbandingan dan pengujian tarik dan impact. (3) Untuk mengetahui patahan dari setiap variasi komposit. (4) Seberapa besar hasil pengujian tarik dan impact. 
Dalam penelitian ini dibatasi antara lain: Pengujian yang di lakukan adalah uji tarik dan uji impact, Bahan pengikat adalah resin, Pengeras yang digunakan adalah katalis, Serat yang digunakan adalah serat kulit kayu jati dari sembarang pohon jati, Cetakan yang di gunakan adalah cetakan yang terbuat dari kaca dengan panjang, lebar dan tinggi $300 \mathrm{~mm}$ x $150 \mathrm{~mm}$ x $5 \mathrm{~mm}$ untuk cetakan pengujian tarik. Cetakan yang di gunakan cetakan yang terbuat dari kaca dengan panjang, lebar dan tinggi $80 \mathrm{~mm}$ x $70 \mathrm{~mm}$ x $15 \mathrm{~mm}$ untuk cetakan pengujian impact.

\section{METODE PENELITIAN}

\section{a. Rancangan Penelitian}

Penelitian ini adalah penelitian eksperimen dengan membuat komposit resin dan penguat serat kulit kayu jati dengan perbandingan 30\% serat kulit kayu jati dengan arah serat yang berbeda dan $70 \%$ resin dari seluruh berat spesimen. Proses pengujian yang dilakukan meliputi: Uji Tarik, dan Uji Impact. Proses perlakuan alkali menggunakan larutan $\mathrm{NaOH}$ sebesar 5\% selama 1 jam. Perbandingan yang di gunakan metriks dengan serat adalah $70: 30$ dari cetakan kaca.

\section{b. Bahan - Bahan Yang Di Gunakan}

Bahan yang di gunakan adalah sebagai berikut :

1) Serat Kulit Kayu Jati

2) Resin polyester type Yukalac C-108B

3) Katalis MEKPO (Methyl Ethyl Ketone Peroxide)

4) $\mathrm{NaOH}$

5) Mirror Glaze

\section{c. Proses Pembuatan Komposit}

Pada proses pembuatan benda uji di butuhkan minimal 3 benda uji dari setiap variasi yaitu, komposit tanpa serat, sertat sejajar, serat anyam dan serat acak sehingga benda uji berjumlah 12 spesimen. Proses pembuatan benda uji komposit untuk pengujian tarik menggunakan standarat ukuran ASTM D3039 kecuali pada tebalnya dan untuk pengujian impact menggunakan ASTM D256-4. Berikut langkah-langkah proses pembuatan benda uji komposit adalah sebagai berikut :

1) Siapkan serat kulit kayu jati lalu bersihkan dari kotoran, kemudian $\mathrm{NaOH}$ ditimbang sebanyak $25 \mathrm{gr}$, lalu larutkan $\mathrm{NaOH}$ sebanyak $500 \mathrm{ml}$ air ersih. 
2) Rendam serat kayu jati di larutan $\mathrm{NaOH} 5 \%$ selama 1 jam.

3) Bersihkan serat yang di rendam $\mathrm{NaOH}$ di air bersih yang mengalir.

4) Rapikan serat kulit kayu jati dan di tata di atas nampan lalu Keringkan serat kulit kayu jati dengan cara menjemurnya di bawah terik matahari hingga kadar airnya berkurang sebanyak $90 \%$.

5) Setelah serat kering lalu potong serat sesuai ukuran yang di tentukan untuk uji tarik serat lurus,acak dan anyam memiliki panjang $200 \mathrm{~mm}$ adapun berat seratnya sendiri 15,52 gr dan untuk uji impek serat lurus dan anyam memiliki panjang $80 \mathrm{~mm}$ dan untuk serat acak memiliki panjang $20 \mathrm{~mm}$ adapun berat seratnya adalah $3,7 \mathrm{gr}$.

6) Rapikan serat pada cetakan yang akan di cetak.

7) Bersihkan cetakan, lalu lapisi mirror glaze pada cetakan yang bertujuan agar hasil benda uji tidak melekat di cetakan.

8) Proses pencampuran, campurkan resin sebanyak 69,7\% dan katalis 0,3\% kemudian aduk perlahan secara merata.

9) Tuangkan campuran resin dan katalis di cetakan, lalu ratakan dengan spatula.

10) Setelah rata letakan serat di atas resin lalu tekan dengan spatula agar serat terendam di dalam campuran resin dan katalis.

11) Tunggu 24 jam agar komposit resin mengering sempurna di suhu ruangan.

12) Setelah kering, lepas komposit dari cetakan, lalu potong dan bentuk komposit sesuai standart yang di tentukan.

13) Komposit siap untuk di uji tarik dan impact.

\section{HASIL DAN PEMBAHASAN}

\section{a. Pengujian Tarik}

Pengujian tarik pada penelitian ini dilakukan untuk mengetahui besarnya kekuatan tarik dan regangan dari komposit. Untuk data dimensi dan hasil pengujian kekuatan tarik dari komposit serat kulit kayu jati, dari beberapa hasil spesimen benda uji metriks (tanpa serat), komposit dengan arah serat sejajar (continous roving), serat anyam (woven roving), dan serat silang. Dari hasil pengujian $\sigma$ (kekuatan tarik) berbagai variasi di dapatkan $\sigma$ (kekuatan tarik) rata -rata dapat dilihat pada diagram tarik pada gambar 7 : 


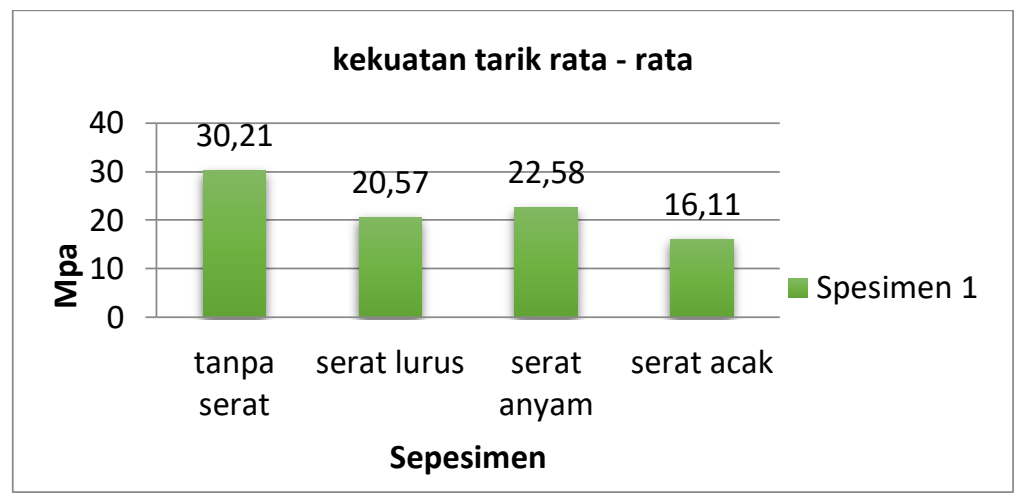

Gambar 7. grafik $\sigma$ (kekuatan tarik)

Dari grafik di atas dapat dianalisis beberapa hal diantaranya adalah:

1) Nilai maksimum rata-rata kekuatan tarik adalah $22,58 \mathrm{MPa}$ (pada variable panjang serat rekel $200 \mathrm{~mm}$ dan persentase volume serat $30 \%$ ) .

2) Kekuatan tarik dari dashboard mobil yang memiliki jenis bahan plastik ABS (akrilonitril butadena stiren) yang dianjurkan dengan standar ISO-527 adalah sebesar 20-40 Mpa, sehingga penelitian ini sudah memenuhi standar.

Dari hasil pengujian $\varepsilon$ (regangan) berbagai variasi di dapatkan $\varepsilon$ (regangan) rata -rata dapat dilihat pada diagram regangan pada gambar 8 :

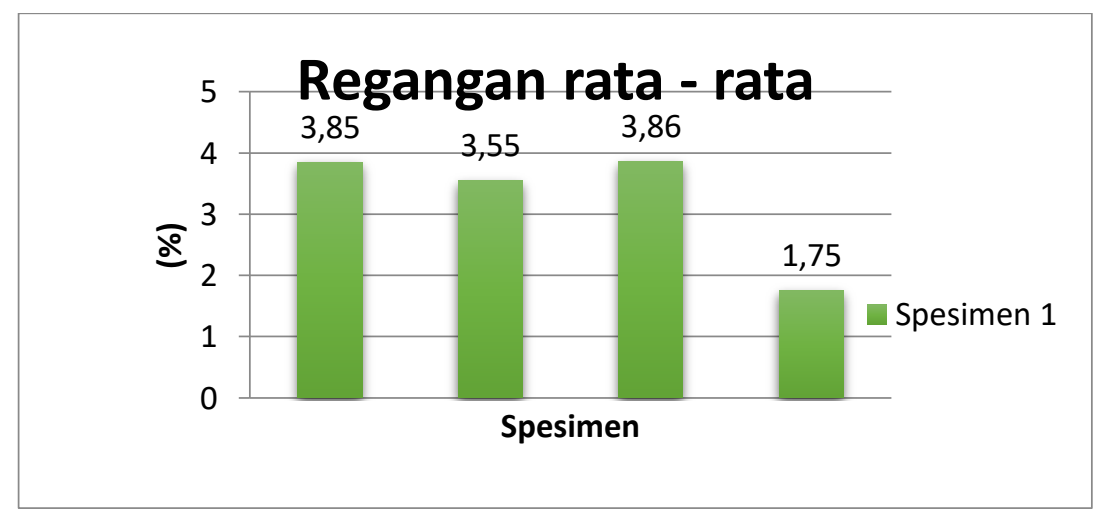

Gambar 8. Grafik Regangan

Dari grafik yang ditampilkan pada Gambar 4.2 inidapat dianalisis beberapa hal diantaranya adalah:

1) Nilai maksimum rata- rata regangannya $3,86 \%$ (pada ukuran panjang serat rekel $200 \mathrm{~mm}$ dan persentase volume serat $30 \%$ ) .

2) Nilai regangan dari dashboard mobil yang memiliki jenis bahan plastik ABS (akrilonitril butadena stiren) yang dianjurkan standar ISO-527 adalah lebih dari $2 \%$. Sehingga penelitian ini sudah memenuhi standart. 
Dari hasil pengujiaan tarik didapat rata- rata kekuatan tarik yang paling tinggi ada pada komposit dengan serat anyam dengan kekuatan tarik rata-rata 22,58 Mpa dan regangan rata - rata paling tinggi ada pada komposit dengan serat anyam dengan regangan sebesar 3,86\%, dari data diatas ada hasil pengujian yang kurang sesuai yang menyebabkan spesimen putus sebelum mencapai beban maksimal tarik sehingga data yang di dapat tidak sesuai yang mengakibatkan putus secara tidak maksimal sehingga data yang di dapat tidak valid dalam proses pengujian.

\section{b. Pengujian Impact}

Dalam pengujian mekanik, terdapat perbedaan dalam pemberian jenis beban kepada material. Uji tarik, uji tekan, dan uji puntir adalah pengujian yang menggunakan beban statik. Sedangkan uji impak menggunakan jenis beban dinamik. Pada uji impak, digunakan pembebanan yang cepat (rapid loading). Perbedaan dari pembebanan jenis ini dapat dilihat pada strain ratenya. Pada pembebanan cepat atau disebut dengan beban impak, terjadi proses penyerapan energi yang besar dari energi kinetik suatu beban yang menumbuk kespesimen.

Untuk menilai ketahanan material terhadap patah getas perlu adanya pengujian yang juga mempertimbangkan faktor-faktor dinamis yang dapat mempengaruhi patah getas antara lainkecepatan regang, takik, tebal bahan yang diuji, tegangan sisa dan lain-lain. Ketangguhan (impact) merupakan ketahanan bahan terhadap beban kejut. Inilah yang membedakan pengujian impak dengan pengujian tarik dan kekerasan dimana pembebanan dilakukan secara mendadak. Grafik 9-10 yang menunjukan besar harga impact dan energi terserap impact.

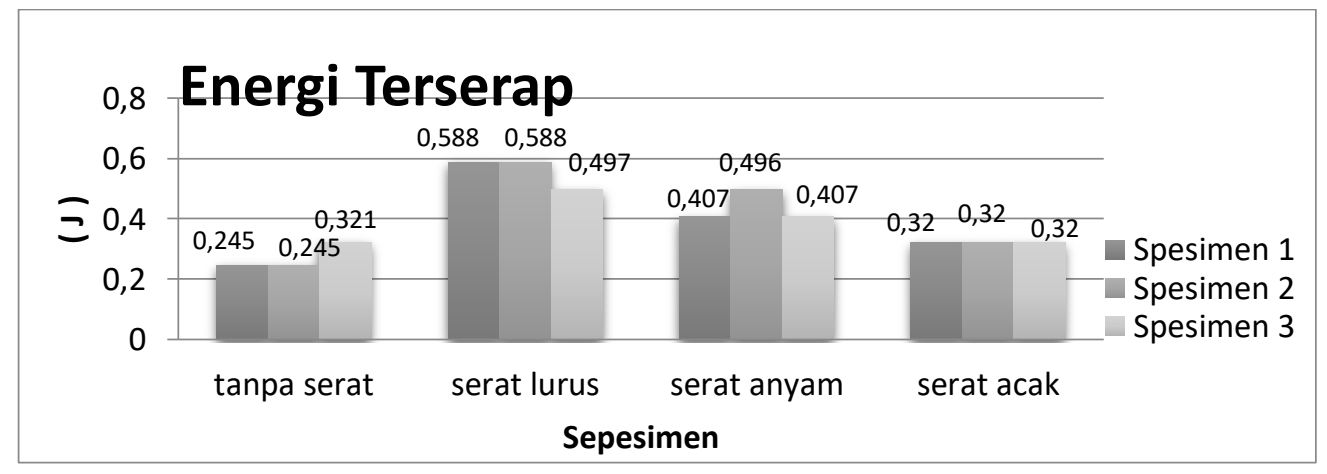

Gambar 9. Grafik Energi Terserap 


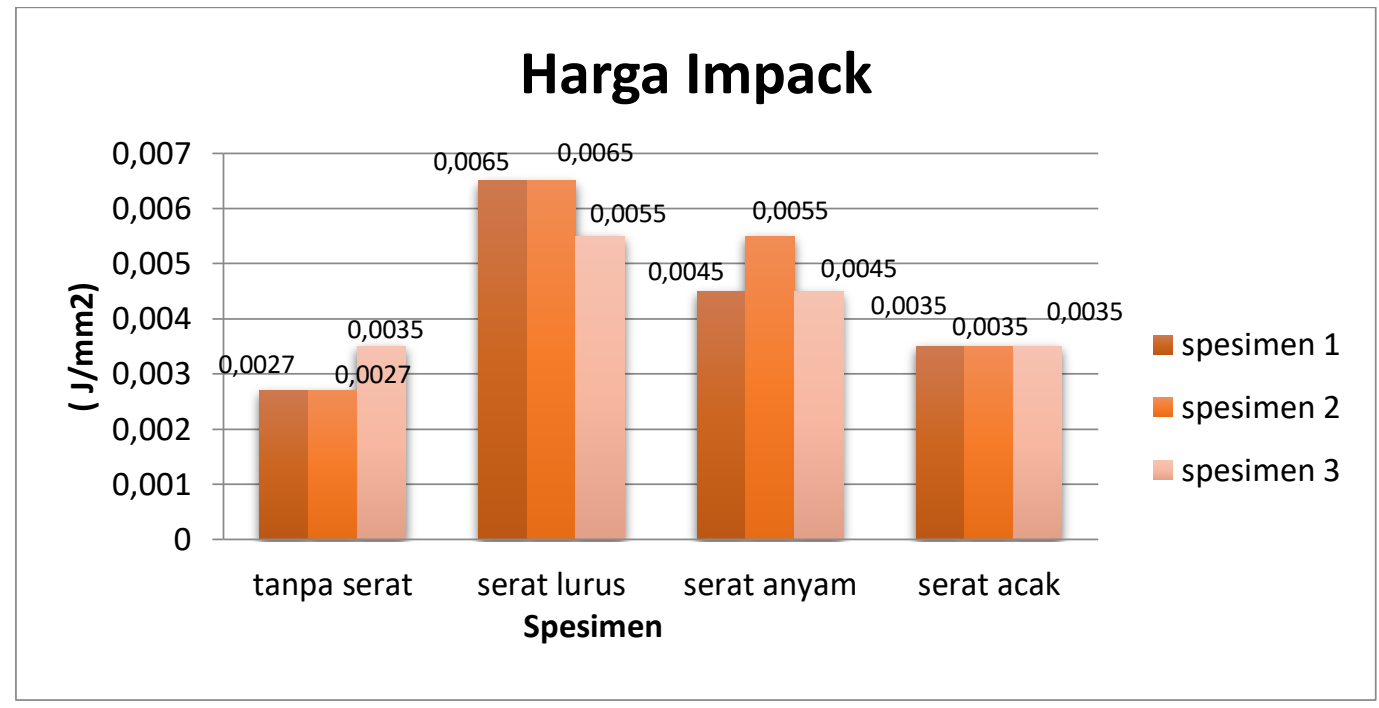

Gambar 10. Grafik Harga Impact

Dari hasil pengujian yang di lakukan dengan variasi yang berbeda - beda, didapatkan hasil energi terserap yang paling tinggi ada pada komposit serat lurus dengan serapan energi 0,588 joule dan hasil dari harga impact tertinggi ada pada komposir serat lurus dengan harga impact $0,0065 \mathrm{~J} / \mathrm{mm}^{2}$. Dari hasil tersebut menunjukkan penambahan fraksi semakin rapat susunan serat di dalam komposit menimbulkan nilai serap dan nilai kekuatanya semakin meningkat hal ini dikarenakan gaya yang akan diterima oleh matriks akan diteruskan keserat penguatnya. Dari masing - masing lapisan serat diambil nilai rata - rata dari energi terserap dan harga impact. Diagram rata - rata energi terserap dan harga impact komposit pada gambar 11-12:

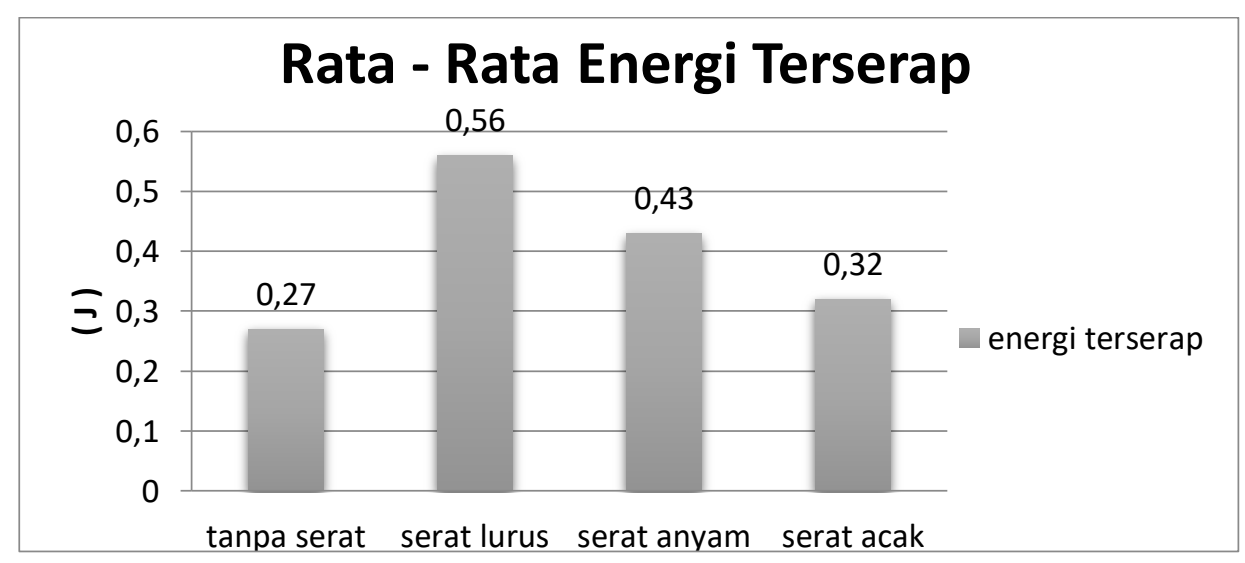

Gambar 11. Grafik Rata - Rata Energi Terserap 


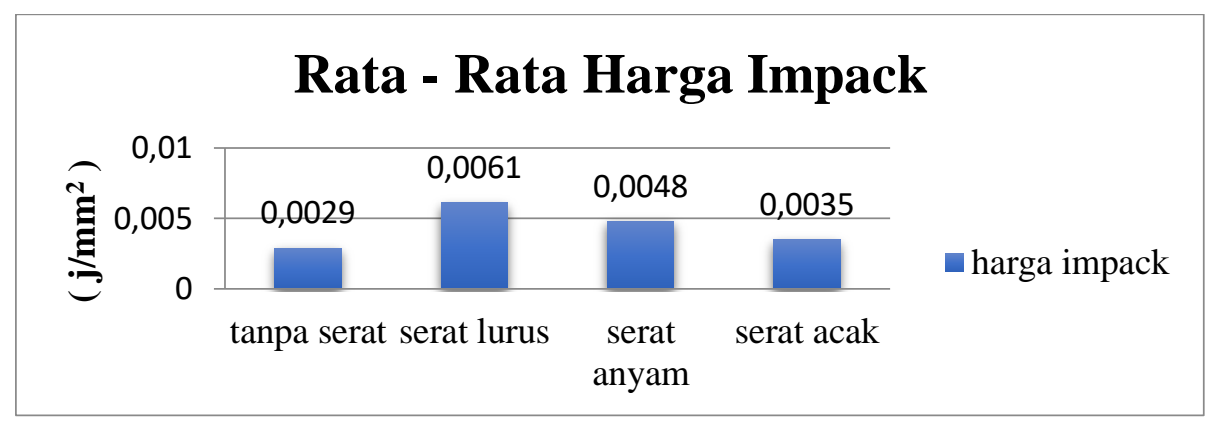

Gambar 12. grafik Rata - ta Harga Impact

Dari hasil pengujian yang di lakukan dengan variasi yang berbeda - beda, di dapatkan hasil energi terserap rata - rata yang paling tinggi Dari grafik yang ditampilkan, dapat dianalisis beberapa hal diantaranya adalah:

1) Nilai maksimum tegangan impact rata -rata adalah $0,0061 \mathrm{~J} / \mathrm{mm}^{2}$ (pada ukuran panjang serat $80 \mathrm{~mm}$ dan prosentase volume serat $30 \%$ ).

2) Untuk kekuatan impact dari dashboard mobil yang memiliki jenis bahan plastik ABS adalah minimal standar ISO-179 sebesar 0,01348 J/mm², sehingga hasil penelitian ini dari segi uji impact belum dapat memenuhi standar dashboard mobil.

Ada pada komposit serat lurus dengan serapan energi sebesar 0,56 joule dan hasil dari harga impact tertinggi ada pada komposir serat lurus dengan harga impact $0,0061 \mathrm{~J} / \mathrm{mm}^{2}$. Dari hasil rata-rata tersebut di ketahui bahwa penjang, pemakaian serat, serta kerapatan serat sangat berpengaruh besar dalam pengujian impact.

\section{SIMPULAN DAN SARAN}

\section{a. Simpulan}

Dari penelitian yang di lakukan penulis dapat di ambil kesimpulan :

1) Hasil dari pengujian tarik komposit berdasarkan variasi arah serat kulit kayu jati yang paling optimal dan terbaik adalah komposit dengan arah serat anyam dan hasil dari kuat tarik yang paling rendah ada pada komposit dengan arah serat acak.

2) Pada pengujian impact yang paling optimal dengan nilai tertinggi adalah pengujian impact komposit dengan serat lurus sedangkan untuk nilai pengujian impact komposit yang terendah adalah komposit dengan serat acak. 
3) Dari hasil pengujian tarik dan impak dengan variasi arah serat kulit kayu jati yang paling baik dan memiliki hasil yang optimal adalah komposit dengan arah serat lurus dan anyam.

4) Dari hasil pengujian yang dilakukan, matrial komposit serat kulit kayu jati memiliki potensi sebagai bahan standar dan pembanding pembuatan dashboard mobil pedesaan.

\section{b. Saran}

Dari penelitian yang sudah dilakukan masih banyak kekurangan dan kesalahan, untuk menyempurnakan penelitian selanjutnya perlu diperhatikan hal - hal sebagai berikut : Pada saat pengujian diperlukan jumlah spesimen yang lebih banyak, agar nilai rata-rata (mean) yang diperoleh lebih akurat. Perlu adanya variasi tebal dan lebar serat yang lebih banyak sehingga dapat diketahui sejauh mana serat kulit kayu jati dapat memberikan pengaruh dalam menambah kekuatan tarik maupun kekuatan impact terhadap komposit resin.

\section{DAFTAR PUSTAKA}

[1] Setiabudi, Rudi. Material Teknik Listrik, UI Press. Jakarta. 2007

[2] Rangkuti, Zulkarnain. 2011. Pembuatan Dan Karakterisasi Papan Partikel Dari Campuran Resin Polyester Serat Kulit Jagung”.Tesis. Medan: FMIPA,USU.

[3] Mather, R.R., and Wardman, R.H. 2011. The chemistry of textile fibres. RSC Publishing. London

[4] Sumarna, D. 2011. Kayu Jati Panduan Budidaya dan Prospek Bisnis. Buku. Penebar Swadaya. Depok. 18--21 p.

[5] Parlevliet, Patricia, P., Bersee, Harald, E.,N., Beukers, Ardian, 2006, Residual stresses in thermoplastic composite-A study of the literaturePart I: Formation of residual stresses, Composites: Part A 37, 18471857John, M.J., and Thomas, S., 2008. Biofibers and biocomposites, Carbohydrate Polymers.71: 343-364. 